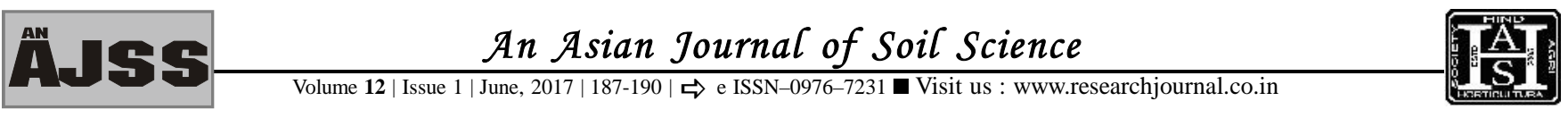

\title{
Assessment of water quality of river Navua, Fiji for irrigation purpose
}

INDRARAJ SINGH AND SAURINDRANR GOSWAMI

MEMBERS OF RESEARCH FORUM:

Corresponding author : INDRA RAJ SINGH, College of Agriculture, Fisheries and Forestry, Fiji National University, Koronivia Campus, Republic of Fiji, FIJI Email: indrarajsingh@gmail.com

Co-authors :

SAURINDRA NR. GOSWAMI, College of Agriculture, Fisheries and Forestry, Fiji National University, Koronivia Campus, Republic of Fiji, FIJI HAS/AJSS/12.1/187-190.
Received : 08.02.2017; Revised : 12.05.2017; Accepted : 23.05.2017

\section{Summary}

Quality of water has been a major concern due to ever increase in human development activities that over exploit and pollute the water resources. Water resources like rivers, lakes, canals etc. are generally used for agricultural production in most of the countries. The sustainable agricultural development depends on the efficient utilization of existing water resources; therefore, quality of irrigation water is an important criteria of consideration for sustainable agricultural production. Various scientific methods are generally used for determination of water quality. This paper is an attempt to analyze the water quality of river Navua in Fiji for irrigation purpose. Water samples for laboratory testing were collected from 6 different sampling sites. Water quality variables were measured and the samples were analyzed for $\mathrm{pH}$, electrical conductivity (EC), total soluble salts (TSS), chloride content (CC), residual sodium carbonate (RSC) and sodium adsorption ratio (SAR). The evaluation of the irrigation water quality parameters as an indicator in the Navua River are summarized in this article.

Key words : Navua river, Irrigation water quality, Chloride, SAR, RSC

How to cite this article : Singh, Indra Raj and Goswami, Saurindra Nr (2017). Assessment of water quality of river Navua, Fiji for irrigation purpose. Asian J. Soil Sci., 12 (1) : 187-190 : DOI : 10.15740/ 